\title{
Effect of Gas Bottom Blowing Condition on Mixing Molten Iron and Slag inside Ironmaking Smelter
}

\author{
Chau-Jeng Su${ }^{1, * 1}$, Jaw-Min Chou ${ }^{1, * 2}$ and Shih-Hsien $\mathrm{Liu}^{2}$ \\ ${ }^{1}$ Department of Materials Science and Engineering, I-SHOU University, \\ No. 1, Sec. 1, Syuecheng Rd., Dashu Township, Kaohsiung 84001, Taiwan, R.O. China \\ ${ }^{2}$ Iron Making Process Development Section, Steel \& Aluminum Research \& Development Dept., China Steel Corporation, \\ No. 1, Chung-Kang Rd., Siaogang District, Kaohsiung 81233, Taiwan, R.O. China
}

In order to increase the productivity, the gas bottom blowing technique has been widely applied to mix molten iron/slag inside the ironmaking smelter. The main function of the technique is to increase the interface area between slag and iron, then to enhance the rate of the smelting reduction. In this study, the simulated experiments of the ironmaking smelter using water model were conducted to investigate the mixing degree of molten iron/slag under different gas bottom blowing conditions. In the experiments, the major parameters of the gas bottom blowing were the inside diameter of tuyere $(6.0$ to $15.0 \mathrm{~mm})$, the total gas flow rate (320 to 480 normal liter/min), the placement of the bottom blowing tuyeres, and the stirring energy. In the water model, water and spindle oil were selected to be the substitute of liquid iron and molten slag, respectively, inside the smelter. Additionally, thymol was used as the tracer of mass transfer between the water phase and the oil phase. Based on the mass transfer rate equation with the analyzed data of thymol concentration during experiments, the mixing degree could be distinguished for different blowing conditions.

In this study, it was found that the mixing degree of water and oil in the case of $10.0 \mathrm{~mm}$ inner diameter tuyere was higher than those of other size tuyeres under the same gas flow rate via 4 tuyeres. Also, the mixing degree increased with increasing the total gas flow rate. Additionally, the mixing degree in the case of 4 tuyeres in the square-corner placement was higher than that in the triangle-corner-center placement at the same tuyere size and total gas flow rate. If considering both mixing efficiency and the gas consumption, the best choice of blowing condition would be four tuyeres of $10.0 \mathrm{~mm}$ diameter in the square-corner placement under the total gas flow rate of 320 normal liter/ min. [doi:10.2320/matertrans.MRA2008434]

(Received November 27, 2008; Accepted March 19, 2009; Published May 13, 2009)

Keywords: gas bottom blowing, ironmaking smelter, mixing degree, molten iron and slag, water model

\section{Introduction}

The direct smelting reduction method of iron ore is one of innovative iron-making processes. Entering the ironmaking smelter, iron ore is heated firstly, then melted into the molten slag phase, and finally reduced to molten iron. Basically, the major reduction of liquid iron oxides occurs at the interface between molten slag and liquid iron. Its reaction mechanism is that liquid iron oxides are reduced by the dissolved carbon of liquid iron. From the viewpoint of reaction kinetics, enlargement of the interface area between molten slag and liquid iron can increase the smelting reduction rate, then enhance the productivity of the iron-making process. In fact, the mixing efficiency of molten iron with slag significantly affects the reaction efficiency inside the ironmaking smelter. Therefore, the purpose of this study was to investigate the effect of gas bottom blowing condition on mixing molten iron and slag inside ironmaking smelter using the simulation technique of water model experiments, then provides process design and operation useful information to enhance the productivity $^{1,2)}$ of the process.

Basically, the function of the gas bottom blowing in the ladle is different from that in the ironmaking smelter. In steel refining, the main function of the gas bottom blowing is to make the distribution of temperature and chemical composition more uniform inside the vessel. In order to suppress the inclusion formation inside the steel slab, the stirring intensity should be controlled under a certain level to prevent slag

\footnotetext{
${ }^{* 1}$ Graduate Student, I-SHOU University

${ }^{* 2}$ Corresponding author, E-mail: jmchou@isu.edu.tw
}

entrapment in the liquid steel. Hence, phenomena observed and data collected about the gas bottom blowing in the case of the refining ladle can not be applied correctly to the case of the ironmaking smelter.

In fact, it is extremely difficult to visually observe phenomena and directly measure properties of the fluid flow field inside pyrometallurgical vessels due to extremely high temperature of fluids. Therefore, water model technique has been adopted to simulate the flow behavior of molten iron and slag inside the vessel in some related research works. $^{1-10)}$ Joo et al., ${ }^{11)}$ Chung et al., ${ }^{12)}$ Zhu et al. ${ }^{9)}$ and Turkoglu et $a{ }^{13)}$ adopted the water model technique to measure the mixing time in the simulated experiments to investigate mixing efficiency inside the refining ladle of steelmaking. In their studies, common conclusions are summarized as follows: As a tuyere was located on the symmetrical center of the bottom of a water model, the flow field was symmetrical and the mixing efficiency was low. Comparatively, in the case of off-centered placement of the tuyere on the bottom, the more turbulent flow and the higher mixing efficiency was obtained under the same gas blowing condition. Matway et al., ${ }^{3)}$ and Mazumdar et al. ${ }^{4)}$ applied the water model technique to investigate the fluid flow inside the converter and the ladle, respectively. Their results indicated that the mixing efficiency resulted from gas bottom blowing via multiple tuyeres with a center tuyere was better than that without a center tuyere. Huang ${ }^{5)}$ adopted a water model to simulate the mixing degree of molten iron and slag in an ironmaking smelter. The results of the research showed that the mixing degree increased with increasing the total gas flow rate and the number of tuyere. The effect of the tuyere 


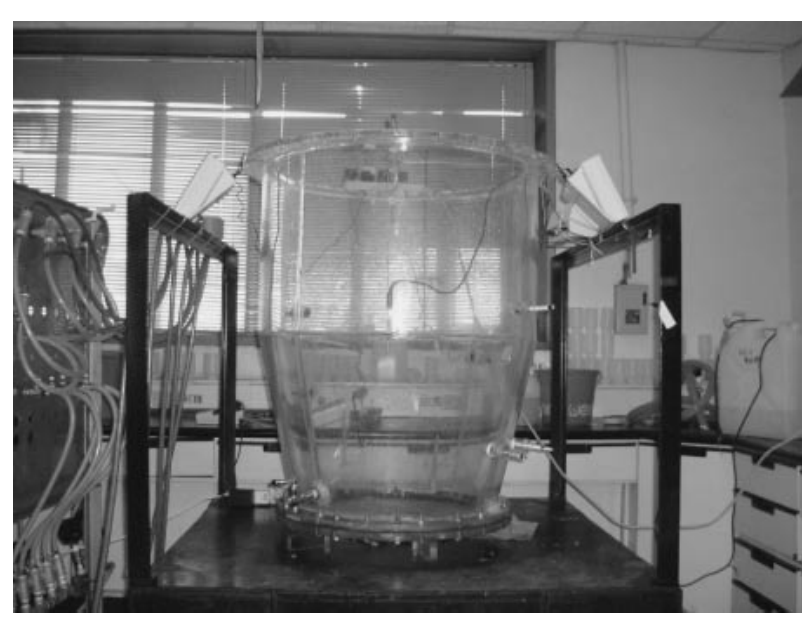

Fig. 1 Photograph of the water model.

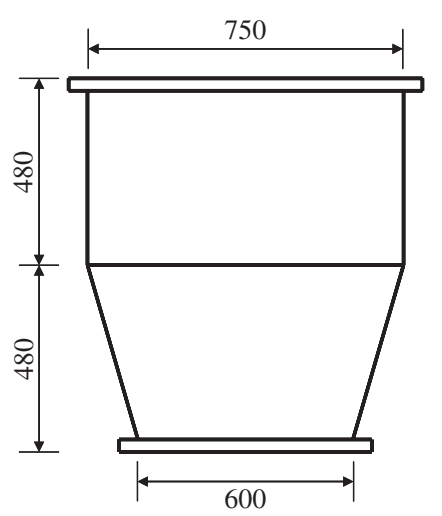

(Dimension Unit: $\mathrm{mm}$ )

Fig. 2 Dimensions of the transparent acrylic water model.

placement on the mixing efficiency was not studied in his research.

In this study, the simulated experiments of the ironmaking smelter using the water model technique were conducted to investigate the mixing degree of molten iron/slag under different gas bottom blowing conditions. The target of the research is to search the gas bottom blowing condition for generating high mixing efficiency of the molten iron and slag in a pilot ironmaking smelter.

\section{Experimental Apparatus and Procedure}

\subsection{Experimental apparatus}

A transparent acrylic water model, shown in Fig. 1 and Fig. 2, is geometrically $60 \%$ scale-down from the pilot ironmaking smelter designed by China Steel Corporation. Figure 3 is a schematic diagram showing that water model experiment. In the experiments, gas was blown via 4 tuyeres installed on the bottom of the water model. The major experimental parameters were the inside diameter of tuyere (6.0 to $15.0 \mathrm{~mm})$, the total gas flow rate $(320$ to $480 \mathrm{NL} / \mathrm{min})$ and the placement of the bottom blowing tuyeres, schematically illustrated in Fig. 4. The detailed values of the parameters are listed in Table 1.

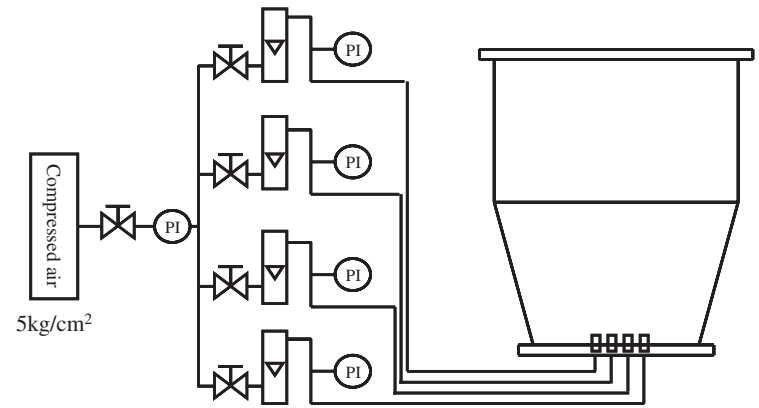

凶: valve ; P : manometer ; $\nabla$ : gas flow meter $\mathbf{\square}$ : tuyere

Fig. 3 Schematic diagram of the gas flow system used in the water model experiments.

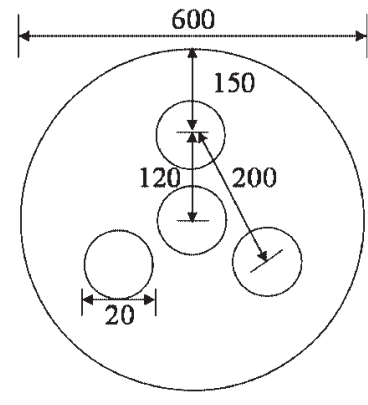

(a)

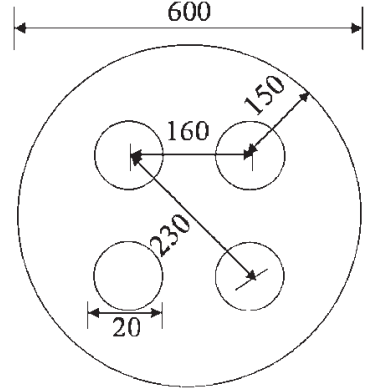

(b)
(Dimension Unit: $\mathrm{mm}$ )

Fig. 4 The position of four tuyeres on the bottom of the water model. (a) triangle-corner-center placement, (b) square-corner placement.

Table 1 Operating parameters of gas bottom blowing used in the water model experiment.

\begin{tabular}{c|c|c|c|c|c}
\hline Tuyere size $(\mathrm{mm})$ & 6.0 & 7.5 & 10.0 & 12.5 & 15.0 \\
\hline Total gas flow rate (NL/min) & 320 & \multicolumn{2}{|c|}{400} & & \multicolumn{2}{c}{480} \\
\hline Tuyere placement & &
\end{tabular}

\subsection{Measurement method of mixing efficiency}

In the simulated experiments, water and spindle oil were selected to be the substitute of molten iron and slag, respectively. Also, compressed air was substituted for the bottom-blown nitrogen of the ironmaking smelter. During the experiments, the water model was filled with the water of $480 \mathrm{~mm}$ height. Next, concentrated thymol solution was poured into the water until the thymol concentration reaches $100 \mathrm{ppm}$ level. After that, a plastic film was used to completely cover the water phase, then spindle oil was lightly and slowly poured onto the plastic film until the oil phase reaches the thickness of $80 \mathrm{~mm}$. Right before gas bottom blowing, the plastic film was quickly drawn away to 
initiate the contact between water and oil. During experiments, water samples were taken at different elapsed time from the starting-point of gas blowing. As gas stirring proceeded, water samples were taken at the times of $0,5,10$, $15,30,60,120,180,240,360,420$, and 480 seconds from the side ( $12 \mathrm{~cm}$ above the bottom) of the water model to measure these thymol concentrations. Also, thymol concentration of water samples was analyzed by an ultraviolet visible spectrophotometer at the wavelength of $273.6 \mathrm{~nm}$. The variation of thymol concentration of the water phase with the mixing time was used to estimate the mixing efficiency.

Based on mass transfer theory, the equation of the mass transfer rate between two phases ${ }^{3,6,10)}$ can be expressed. In this study, thymol diffused from the water phase to the oil phase during the experiments. The volume of water phase and oil phase can be assumed to be constant. Based on the Matway et al. ${ }^{3)} \mathrm{Kim}$ et al. ${ }^{6)}$ and Chou et al. ${ }^{10)}$ indicated that, the following equations can be derived. Whereas, the assumptions are made in these equations: 1. Mass transfer of the water phase boundary layer is assumed to be the rate controlling step. 2. Equilibrium is assumed be attained at the interface.

$$
\begin{aligned}
& d C_{\mathrm{w}} / d t=-k_{\mathrm{w}} A / V_{\mathrm{w}}\left(C_{\mathrm{w}}-C_{\mathrm{w}}^{\prime}\right) \\
& h=C_{\mathrm{w}}^{\prime} / C_{\mathrm{o}} \\
& \left(C_{\mathrm{w}}^{0}-C_{\mathrm{w}}\right) V_{\mathrm{w}}=C_{0} V_{0} \\
& \int_{C_{\mathrm{w}}^{0} 0}^{C_{\mathrm{w}}} \frac{d C_{\mathrm{w}}}{\left(1+h V_{\mathrm{w}} / V_{0}\right) C_{\mathrm{w}}-h C_{\mathrm{w}}^{0} V_{\mathrm{w}} / V_{0}}=-\frac{k_{\mathrm{w}} A}{V_{\mathrm{w}}} \int_{0}^{t} d t \\
& \frac{-\ln \left[\left(1+h V_{\mathrm{w}} / V_{0}\right) C_{\mathrm{w}} / C_{\mathrm{w}}^{0}-h V_{\mathrm{w}} / V_{0}\right]}{1+h V_{\mathrm{w}} / V_{0}}=\frac{k_{\mathrm{w}} A}{V_{\mathrm{w}}} t
\end{aligned}
$$

Where

$h$ : equilibrium partition ratio of thymol between water and oil phases.

$C_{\mathrm{w}}^{\prime}$ : equilibrium concentration of thymol in the water phase at the interfce $\left(\mathrm{mole} / \mathrm{cm}^{3}\right)$.

$C_{\mathrm{o}}$ : concentration of thymol in the oil phase $\left(\mathrm{mole} / \mathrm{cm}^{3}\right)$.

$V_{\mathrm{w}}$ : volume of water phase $\left(\mathrm{cm}^{3}\right)$.

$V_{\mathrm{o}}$ : volume of oil phase $\left(\mathrm{cm}^{3}\right)$.

$C_{\mathrm{w}}$ : concentration of thymol in the water phase at time $t$ $\left(\mathrm{mole} / \mathrm{cm}^{3}\right)$.

$C_{\mathrm{w}}^{\mathrm{o}}$ : initial concentration of thymol in the water phase $\left(\mathrm{mole} / \mathrm{cm}^{3}\right)$.

Hereafter, the left hand side of eq. (5) is abbreviated as LHS. The thymol concentration in the water phase $\left(C_{\mathrm{w}}\right)$ is only variable in LHS during the experiment. $h$ value can be obtained experimentally from the measured concentration of thymol between the two phases at equilibrium, and the experimental result can be shown by Fig. 5. From Fig. 5, it can also be known that the $h$ value is about 0.0676 . Based on eq. (5) with experimental data, if LHS is plotted against mixing time, a straight line could be obtained. The slope of the line is $\left(-k_{\mathrm{w}} A / V_{\mathrm{w}}\right)$. As $V_{\mathrm{w}}$ and $k_{\mathrm{w}}$ can be regarded as constant, the value of $k_{\mathrm{w}} A$, volumetric mass transfer coefficient, would be obtained and used to indicate the relative magnitude of the interfacial area between two phases for different experiments. The higher value of $k_{\mathrm{w}} A$ means the more interfacial area and the higher mixing efficiency between two phases.

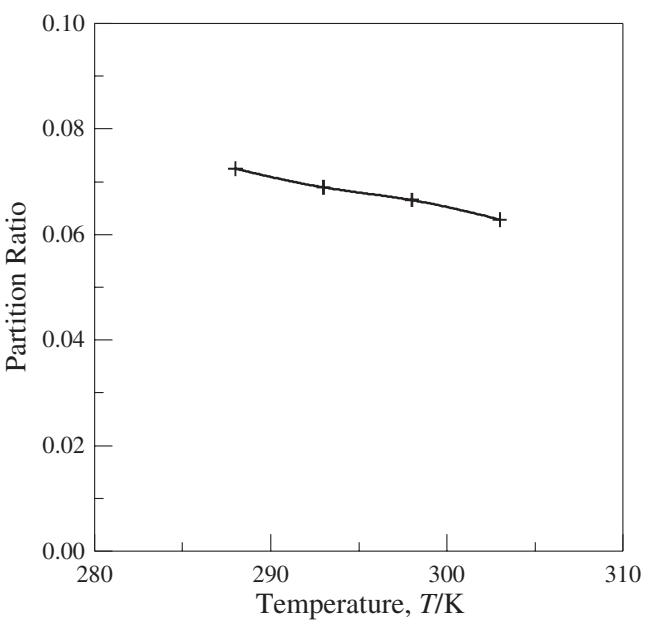

Fig. 5 Relationship between temperature and equilibrium partition ratio of thymol.

\subsection{Similarity conversion between water model and ironmaking vessel}

In order to simulate the gas stirring condition inside the ironmaking vessel, the equivalence of modified Froude number $\left(N_{\mathrm{Fr}}^{\prime}\right)$, a dimensionless group expressed as eq. (6), was relied upon to estimate the gas blowing condition of the water model. The physical meaning of modified Froude number represents the ratio of the kinetic energy of the injected gas to the potential energy of the stirred liquid. According to Kim et al., ${ }^{6}$ it was considered as the similarity criterion to correlate the gas flow rate between the scale model and full scale system, such as eqs. (6) to (11). Under the similarity of two systems, the gas flow rate via the tuyere of a certain diameter adopted in the water model can be estimated by eq. (11) with the gas blowing condition of the ironmaking vessel. The derivation of eq. (11) from eq. (6) is explained as below:6)

$$
N_{\mathrm{Fr}}^{\prime}=\frac{\rho_{\mathrm{g}} U_{T}^{2}}{\rho_{\mathrm{l}} g L}=C \frac{Q^{2}}{L d^{4}}
$$

where

$$
C=9.159 \times 10^{-10}\left(M^{2} / \rho_{\mathrm{g}} \rho_{\mathrm{l}}\right)
$$

$\rho_{\mathrm{g}}$ : density of gas $\left(\mathrm{g} / \mathrm{cm}^{3}\right)$

$\rho_{1}$ : density of liquid $\left(\mathrm{g} / \mathrm{cm}^{3}\right)$

$g$ : gravitational acceleration $\left(980 \mathrm{~cm} / \mathrm{s}^{2}\right)$

$L$ : liquid height $(\mathrm{cm})$

$Q$ : gas flow rate $\left(\mathrm{m}^{3} / \mathrm{s}\right)$

$U_{T}$ : velocity of gas injection $(\mathrm{cm} / \mathrm{s})$

$M$ : molecular weight of gas $(\mathrm{g} /$ mole $)$

$d$ : internal diameter of tuyere $(\mathrm{cm})$

$C$ : constant term

$$
\begin{aligned}
& \text { Water Model } \rightarrow N_{\mathrm{Fr},(\mathrm{wm})}^{\prime}=C_{\mathrm{wm}} \frac{Q_{\mathrm{wm}}^{2}}{L_{\mathrm{wm}} d_{\mathrm{wm}}^{4}} \\
& \text { Ironmaking Vessel } \rightarrow N_{\mathrm{Fr},(\mathrm{iv})}^{\prime}=C_{\mathrm{iv}} \frac{Q_{\mathrm{iv}}^{2}}{L_{\mathrm{iv}} d_{\mathrm{iv}}^{4}}
\end{aligned}
$$

Where $N_{\mathrm{Fr}}^{\prime}($ Water Model $)=N_{\mathrm{Fr}}^{\prime}$ (Ironmaking Vessel)

$$
C_{\mathrm{wm}} \frac{Q_{\mathrm{wm}}^{2}}{L_{\mathrm{wm}} d_{\mathrm{wm}}^{4}}=C_{\mathrm{iv}} \frac{Q_{\mathrm{iv}}^{2}}{L_{\mathrm{iv}} d_{\mathrm{iv}}^{4}}
$$




$$
\begin{aligned}
& \Rightarrow \frac{Q_{\mathrm{wm}}^{2}}{Q_{\mathrm{iv}}^{2}}=\left(\frac{C_{\mathrm{iv}}}{C_{\mathrm{wm}}}\right)\left(\frac{L_{\mathrm{wm}} d_{\mathrm{wm}}^{4}}{L_{\mathrm{iv}} d_{\mathrm{iv}}^{4}}\right) \\
& \Rightarrow \frac{Q_{\mathrm{wm}}}{Q_{\mathrm{iv}}}=\left(\frac{C_{\mathrm{wm}}}{C_{\mathrm{iv}}}\right)^{-\frac{1}{2}} \lambda^{\frac{5}{2}} \\
& \Rightarrow Q_{\mathrm{wm}}=\left(\frac{C_{\mathrm{wm}}}{C_{\mathrm{iv}}}\right)^{-\frac{1}{2}} \lambda^{\frac{5}{2}} Q_{\mathrm{iv}}
\end{aligned}
$$

where

$Q_{\mathrm{wm}}$ : gas flow rate for water model.

$Q_{\mathrm{iv}}$ : gas flow rate for ironmaking vessel.

$C_{\mathrm{wm}}$ : constant term for water model.

$C_{\mathrm{iv} .}$ : constant term for ironmaking vessel.

$\lambda$ : geometrical scale factor.

In this study, air was substituted for the bottom-blown nitrogen $\left(\mathrm{N}_{2}\right)$ of the ironmaking smelter. Additionally, the physical properties of hot model system (molten iron/ $\mathrm{N}_{2}$ ) and water model system (water/air) were substituted for eq. (7) respectively, $C_{m}$ and $C_{f, s}$ were known. Then $C_{m}, C_{f, s}$ were substituted for eq. (10), respectively. Therefore, the eq. (11) was applied to this correlation to the system of molten iron $/ \mathrm{N}_{2}$ and water/air.

Then

$$
Q_{\mathrm{iv}}=1.295 \lambda^{-5 / 2} Q_{\mathrm{wm}}
$$

\subsection{Calculation for total energy of blown gas}

In the research of Kishimoto et al. ${ }^{7)}$ and Krishnakumar et al., ${ }^{8)}$ it was indicated that the total energy $\left(\varepsilon_{\text {total }}\right)$ of the blown gas consists of two parts: buoyancy energy and kinetic energy. The gas bubble transfers its buoyancy energy and kinetic energy to the stirred liquid during ascending. The energy transfer makes liquid circulate inside the vessel. The transfer efficiency of the total energy depends on the gas blowing condition. The main purpose of this research was to search the gas blowing condition that could creates high mixing efficiency of molten slag/iron with the low total energy of the blown gas flow. Kinetic energy and buoyancy energy can be calculated using eq. (12) and eq. (13), respectively.

$$
\begin{aligned}
\varepsilon_{\mathrm{k}} & =\frac{1}{2} \dot{m} u_{\mathrm{g}}^{2} \\
\varepsilon_{\mathrm{b}} & =\dot{n} R T_{\mathrm{L}} \ln \frac{P_{1}}{P_{2}}
\end{aligned}
$$

Where

$$
\left\{\begin{array}{l}
\dot{m}=\frac{d m}{d t}=\rho_{\mathrm{g}} \frac{d V}{d t}=\rho_{\mathrm{g}} \times Q \\
u_{\mathrm{g}}=\frac{Q}{A}=\frac{4 Q}{\pi d^{2}}
\end{array}\right.
$$

And, substituting eq. (15) and eq. (16) into eq. (14) can derive

$$
\varepsilon_{\mathrm{k}}=\frac{1}{2} \dot{m} u_{\mathrm{g}}^{2}=\frac{1}{2} \rho_{\mathrm{g}} \times Q \times\left(\frac{4 Q}{\pi d^{2}}\right)^{2}=\frac{8 \rho_{\mathrm{g}} Q^{3}}{\pi^{2} d^{4}}
$$

Where

$\varepsilon_{\mathrm{b}}$ : buoyancy energy (joule/s)

$\varepsilon_{\mathrm{k}}$ : kinetic energy of the injected gas (joule/s)
Table 2 The calculated total energy of the bottom blown gas in the experiments. (Condition: $480 \mathrm{~mm}$ liquid height and four tuyeres)

\begin{tabular}{cccc}
\hline & \multicolumn{3}{c}{ Total Flow Rate (NL/min) } \\
\cline { 2 - 4 } Tuyere Size $(\mathrm{mm})$ & $\mathbf{3 2 0}$ & $\mathbf{4 0 0}$ & $\mathbf{4 8 0}$ \\
\hline $\mathbf{6 . 0}$ & 138.2 & 252.1 & 417.4 \\
\hline $\mathbf{7 . 5}$ & 72.3 & 122.9 & 194.5 \\
\hline $\mathbf{1 0 . 0}$ & 41.0 & 61.6 & 88.7 \\
\hline $\mathbf{1 2 . 5}$ & 32.5 & 44.8 & 59.9 \\
\hline $\mathbf{1 5 . 0}$ & 29.4 & 38.8 & 49.5 \\
\hline & & & (unit: joule)
\end{tabular}

$\dot{n}:$ molar gas flow rate $(\mathrm{mole} / \mathrm{s})$

$R$ : gas constant $(8.314$ joule $/$ mole $\cdot \mathrm{K})$

$T_{\mathrm{L}}$ : temperature of liquid $(\mathrm{K})$

$P_{1}$ : pressure at the liquid bottom (atm)

$P_{2}$ : pressure at the liquid surface (atm)

$\rho_{\mathrm{g}}:$ density of gas $\left(\mathrm{kg} / \mathrm{m}^{3}\right)$

$\dot{m}$ : mass flow rate $(\mathrm{kg} / \mathrm{s})$

$u_{\mathrm{g}}$ : velocity of bottom blown gas $(\mathrm{m} / \mathrm{s})$

$Q$ : gas flow rate $\left(\mathrm{m}^{3} / \mathrm{s}\right)$

$d$ : internal diameter of tuyere $(\mathrm{m})$

Theoretically, the total energy of bottom blown gas can be calculated using the following equation.

$$
\varepsilon_{\text {total }}=\varepsilon_{\mathrm{b}}+\varepsilon_{\mathrm{k}}=\dot{n} R T_{\mathrm{L}} \ln \frac{P_{1}}{P_{2}}+\frac{8 \rho_{\mathrm{g}} Q^{3}}{\pi^{2} d^{4}}
$$

The calculated total energy values with the bottom blown gas under different gas bottom blowing conditions in the experiments are listed in Table 2.

\section{Results and Discussion}

To obtain appropriate sampling times, preliminary water model experiments were conducted with total gas flow rate of 320,400 and $480 \mathrm{NL} / \mathrm{min}$ at the tuyere size of $10.0 \mathrm{~mm}$. The variations of thymol concentration with respect to time were shown in Fig. 6. Then, plotting LHS of eq. (5) vs time for experimental data was shown in Fig. 7. Figure 7 can be seen that, regardless of total gas flow rate, the LHS is drastically increased in the early stage (about 0 to $60 \mathrm{~s}$ ). After $120 \mathrm{~s}$, the LHS remains essentially unchanged. Therefore, according to the above result, this study is taken the slope of the straight line for the period between 0 and $60 \mathrm{~s}$, which can be considered to correspond to $k_{\mathrm{w}} A / V_{\mathrm{w}}$. $V_{\mathrm{w}}$ is the volume of the water phase, a known value. Thus, the $k_{\mathrm{w}} A$ can be determined for all experimental conditions, as a direct index for evaluating the mixing efficiency.

\subsection{Effect of tuyere size on mixing efficiency}

3.1.1 Case of four tuyeres in square-corner placement

Figure 8 indicates that the highest volumetric mass transfer coefficient was obtained at the tuyere size of $10.0 \mathrm{~mm}$ under the total gas flow rate of $480 \mathrm{NL} / \mathrm{min}$. It also indicates that the almost identical mixing degree was obtained at the same tuyere size under the total gas flow rate of $320 \mathrm{NL} / \mathrm{min}$ and $400 \mathrm{NL} / \mathrm{min}$. The mixing degree was obviously enhanced with increasing the gas flow rate up to $480 \mathrm{NL} / \mathrm{min}$. Also, the value of the volumetric mass transfer coefficient is 


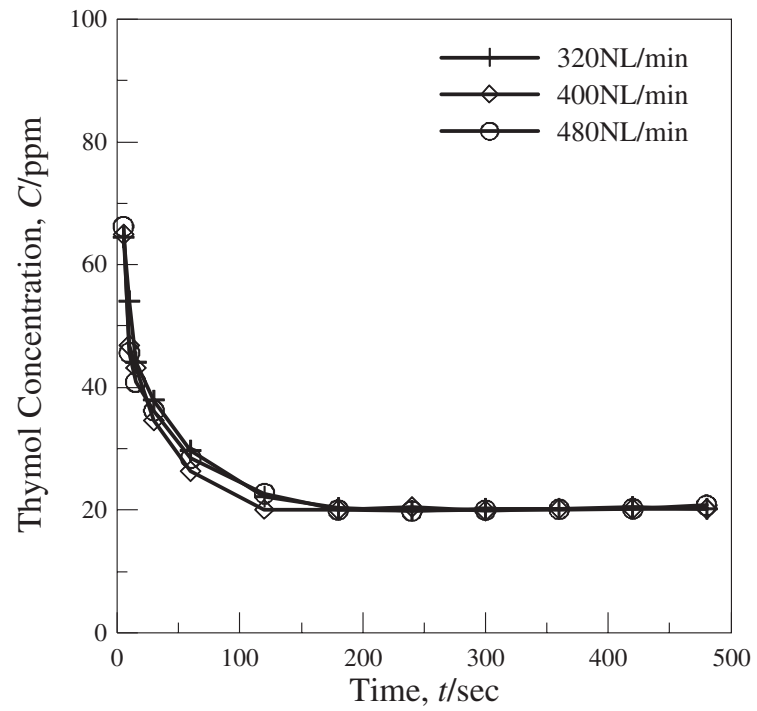

Fig. 6 Relationship between time and thymol concentration at the tuyere size of $10.0 \mathrm{~mm}$ in the triangle-corner-center placement.

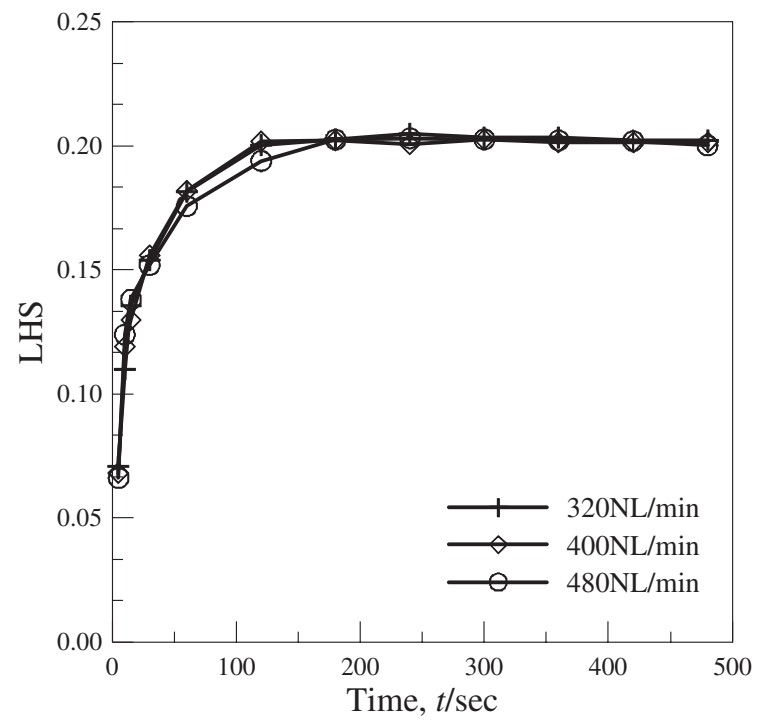

Fig. 7 Relationship between time and LHS at the tuyere size of $10.0 \mathrm{~mm}$ in the triangle-corner-center placement.

almost constant, $1720 \mathrm{~cm}^{3} / \mathrm{s}$, in the range of tuyere size from 6.0 to $10.0 \mathrm{~mm}$ under the gas flow of $480 \mathrm{NL} / \mathrm{min}$.

\subsubsection{Case of four tuyeres in triangle-corner-center placement}

Figure 9 indicates that the volumetric mass transfer coefficient increases with increasing the total gas flow rate at any tuyere size. In the cases of $320 \mathrm{NL} / \mathrm{min}$ and $400 \mathrm{NL} /$ min gas flow rate, the values of the volumetric mass transfer coefficient are almost constant, $1447 \mathrm{~cm}^{3} / \mathrm{s}$ and $1524 \mathrm{~cm}^{3} / \mathrm{s}$, respectively, in the range of tuyere size from 6.0 to $10.0 \mathrm{~mm}$. And, the lowest value of the volumetric mass transfer coefficient is found at the tuyere size of $12.5 \mathrm{~mm}$. Under the total gas flow rate of $480 \mathrm{NL} / \mathrm{min}$. The relationship between the tuyere size and the volumetric mass transfer coefficient showed a characteristic curve of sine wave. The maximum volumetric mass transfer coefficient, $1709 \mathrm{~cm}^{3} / \mathrm{s}$, was obtained at the tuyere diameter of $7.5 \mathrm{~mm}$. The volumetric mass

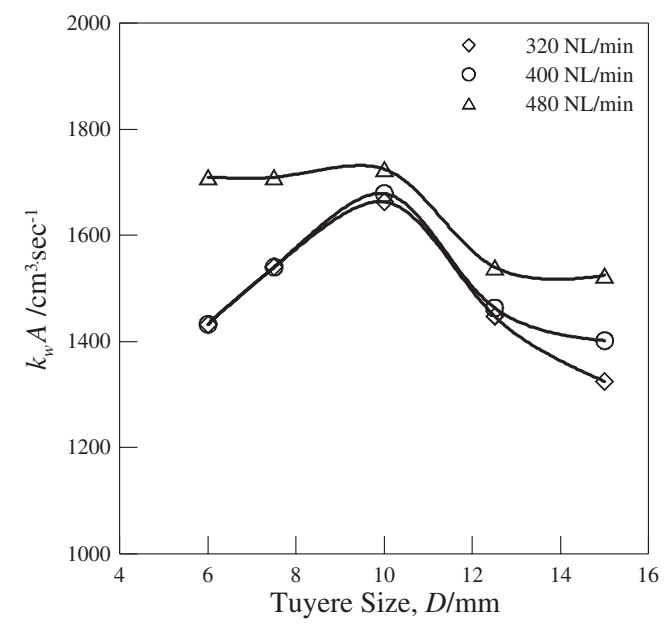

Fig. 8 Relationship between tuyere size and volumetric mass transfercoefficient in the case of four tuyeres in the square-corner placement.

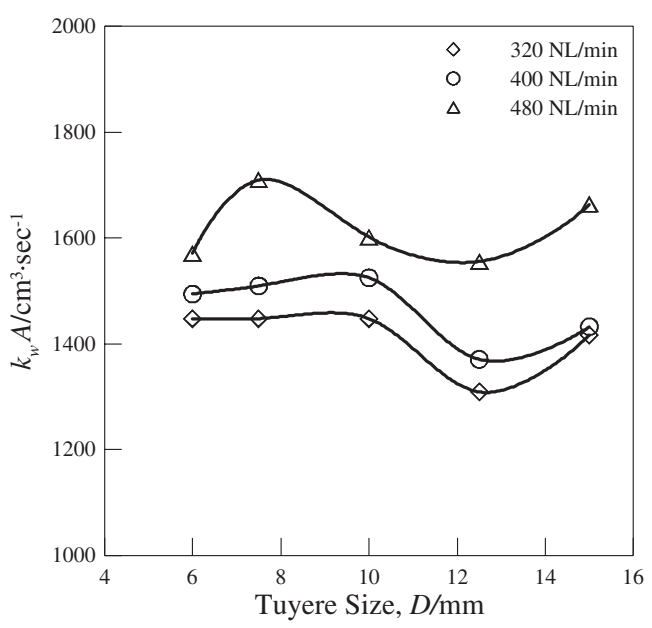

Fig. 9 Relationship between tuyere size and volumetric mass transfer coefficient in the case of four tuyeres in the triangle-corner-center placement.

transfer coefficient decreases with increasing tuyere size ranging from 10.0 to $12.5 \mathrm{~mm}$.

For section 3.1.1 of the case of four tuyeres in squarecorner placement, this phenomenon could be due to the smaller than $10 \mathrm{~mm}$ tuyere, because with the same gas flow rate per single tuyere, as size decreased, the velocity per tyuere increased, which caused the injection gas plume to rush over the surface of the liquid bath. This resulted in the stirring energy disappearing, which made the mixing efficiency worse. However bigger than $10 \mathrm{~mm}$ tuyere, the velocity per tyuere and the energy of injected gas were both smaller, which made a lower mixing efficiency. For section 3.1.2 of case of four tuyeres in triangle-corner-center placement, tuyere size of $7.5 \mathrm{~mm}$ has enough stirring energy to get the highest mixing efficiency.

\subsection{Effect of total energy of blown gas on mixing efficiency}

3.2.1 Case of four tuyeres in square-corner placement

In practice, the total energy of bottom blown gas can be promoted via reducing the tuyere size or increasing the gas 


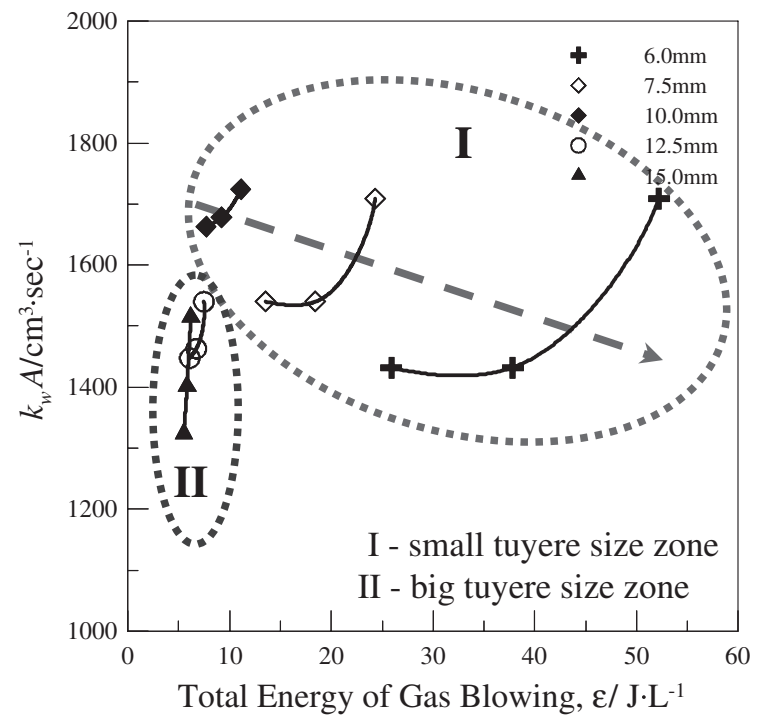

Fig. 10 Relationship between total energy and volumetric mass transfer coefficient in the case of four tuyeres in the square-corner placement.

flow rate. In this case, Fig. 10 shows the relationship between the total energy of bottom blown gas and the volumetric mass transfer coefficient for different tuyere sizes. It can be seen that the volumetric mass transfer coefficient increases with increasing the total energy of bottom blown gas at a fixed tuyere size. In addition, distribution of data in Fig. 10 can be grouped into two characteristic zones, Zone I for small size tuyeres $(6.0 \mathrm{~mm}$ to $10.0 \mathrm{~mm})$ and Zone II for large size tuyeres (12.5 $\mathrm{mm}$ to $15.0 \mathrm{~mm})$.

In Zone I, an increase of total energy of the blown gas via reducing the tuyere size could not enhance the volumetric mass transfer coefficient under the high gas flow rate $(480 \mathrm{NL} / \mathrm{min})$. But under the low gas flow rate (320 and $400 \mathrm{NL} / \mathrm{min}$ ), an increase of total energy of the blown gas via reducing the tuyere size sharply decreases the volumetric mass transfer coefficient. Therefore, to attain an equal volumetric mass transfer coefficient, the required total energy of the blown gas via the tuyeres of $10.0 \mathrm{~mm}$ is lower than the tuyeres of 6.0 and $7.5 \mathrm{~mm}$. This characteristic means that the larger size tuyeres, the lower energy consumed, or the higher mixing efficiency obtained under the same gas flow rate. As mentioned above, the highest mixing degree was obtained at $10 \mathrm{~mm}$ tuyere size in the range of 6.0 to $10.0 \mathrm{~mm}$.

In Zone II, the volumetric mass transfer coefficient sharply increases as the total energy of the blown gas slightly increases, but the volumetric mass transfer coefficients are smaller than those in Zone I under the same total gas flow rate. This characteristic means that the positive effect of the gas flow rate on the mixing degree via the large size tuyeres $(12.5$ and $15.0 \mathrm{~mm})$ is slighter than the smaller ones $(6.0,7.5$ and $10.0 \mathrm{~mm}$ ).

Considering both the mixing efficiency and the energy consumption, the optimal condition of the gas blowing in the case of 4 tuyeres in the square-corner placement was the tuyere size of $10.0 \mathrm{~mm}$ and the total gas flow rate of 400 $\mathrm{NL} / \mathrm{min}$.

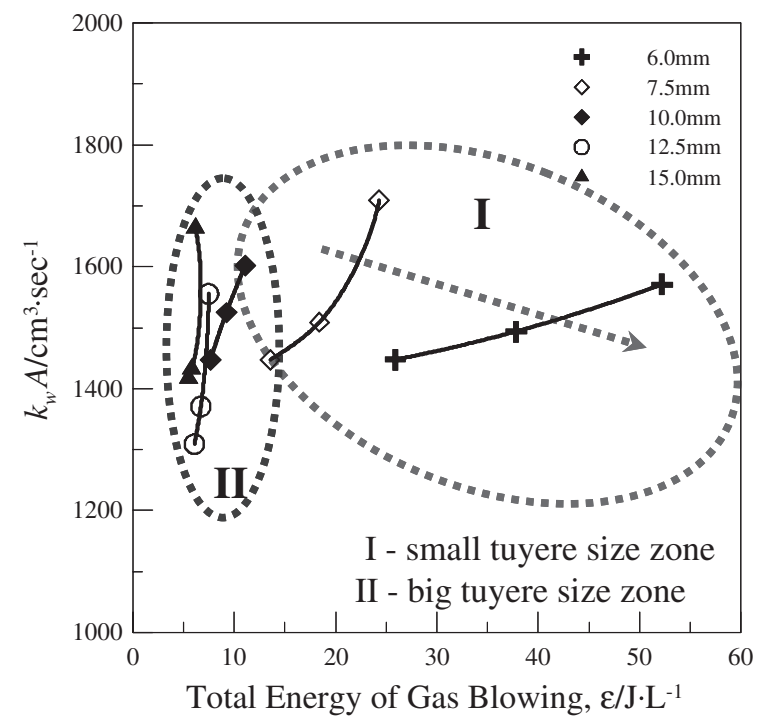

Fig. 11 Relationship between total energy and volumetric mass transfer coefficient in the case of four tuyeres in the triangle-corner-center placement.

\subsubsection{Case of four tuyeres in triangle-corner-center placement}

In Fig. 11, distribution of data can also be grouped into two characteristic zones, Zone I for small size tuyeres $(6.0 \mathrm{~mm}$ to $7.5 \mathrm{~mm})$ and Zone II for large size tuyeres $(10.0 \mathrm{~mm}$ to $15.0 \mathrm{~mm})$. Compared with the previous case, data for $10.0 \mathrm{~mm}$ tuyere are grouped into Zone II of Fig. 11, not grouped into Zone I.

In Zone I, it shows that an increase of total energy of the blown gas via reducing the tuyere size could not enhance the volumetric mass transfer coefficient under the low gas flow rate $(320$ and $400 \mathrm{NL} / \mathrm{min})$. But under high gas flow rate $(480 \mathrm{NL} / \mathrm{min})$, an increase of total energy of the blown gas via reducing the tuyere size obviously decreases the volumetric mass transfer coefficient. In contrast with the case of the square-corner placement, this characteristic occurred at the other bound of the gas flow range. Therefore, to acquire an equal volumetric mass transfer coefficient, the required total energy of the blown gas via the tuyeres of $7.5 \mathrm{~mm}$ is lower than that of $6.0 \mathrm{~mm}$. This characteristic means that the larger size tuyeres, the lower energy consumed, or the higher mixing efficiency obtained under the same gas flow rate. As mentioned above, the highest mixing degree was obtained at $7.5 \mathrm{~mm}$ tuyere size in the range of 6.0 to $7.5 \mathrm{~mm}$.

In Zone II, the volumetric mass transfer coefficient sharply increases as the total energy of the bottom blown gas slightly increases, but the volumetric mass transfer coefficients are smaller than those in Zone I under the same total gas flow rate. This characteristic means that the positive effect of the gas flow rate on the mixing degree via the large size tuyeres $(10.0,12.5$ and $15.0 \mathrm{~mm})$ is slighter than the smaller ones $(6.0$ and $7.5 \mathrm{~mm}$ ).

Considering both mixing efficiency and the energy consumption, the optimal condition of the gas blowing in the case of 4 tuyeres in the triangle-corner-center placement is the tuyere size of $7.5 \mathrm{~mm}$ and the total gas flow rate of $480 \mathrm{NL} / \mathrm{min}$. 
Combined with section 3.2.1 and 3.2.2 were known that, under different total gas flow rate, as the total energy of gas injected was enhanced to the critical total energy, even did not increase the value of volumetric mass transfer coefficient. Viewed in the operating efficiency, too much total energy of gas injected did not enhance mixing degree. Additionally, due to the Placement of the bottom-blowing tuyere influenced energy dissipation, and this most obviously for a center tuyere surrounded by a balance of tuyeres which resulted in energy dissipation from these areas.

In this study, it can be found that the best mixing degree could be achieved in the case of $10.0 \mathrm{~mm}$ tuyeres in the square-corner placement, shown in Fig. 10 and in the case of $7.5 \mathrm{~mm}$ tuyeres in the triangle-corner-center placement, shown in Fig. 11, respectively. If the highest volumetric mass transfer coefficient is pursued firstly, then the lowest total energy consumed in the mixing operation is considered secondly, the best choice for the gas blowing condition should be the case of 4 tuyeres of $10.0 \mathrm{~mm}$ diameter in the square-corner placement with the total gas flow rate of $480 \mathrm{NL} / \mathrm{min}$.

\subsection{Effect of total gas flow rate on mixing degree}

\subsubsection{Case of four tuyeres in square-corner placement}

Figure 12 shows that the relationship between the volumetric mass transfer coefficient increases with increasing the total gas flow rate via the tuyere with different sizes. Under the low gas flow rate $(480 \mathrm{NL} / \mathrm{min})$, the highest value of volumetric mass transfer coefficient is found at the tuyere size of $10.0 \mathrm{~mm}$. Therefore, while considering both mixing efficiency and the gas consumption, $320 \mathrm{NL} / \mathrm{min}$ via the tuyere size of $10.0 \mathrm{~mm}$ would be the first choice.

\subsubsection{Case of four tuyeres in triangle-corner-center placement}

Figure 13 indicates that the mixing degree increased with increasing the total gas flow rate at any tuyere size. In this case, the highest volumetric mass transfer coefficient under the lowest total gas flow $(320 \mathrm{NL} / \mathrm{min})$ is obviously lower than that under the highest one $(480 \mathrm{NL} / \mathrm{min})$. It means that the high mixing efficiency would not be achieved under the low total gas flow rate via four tuyeres in the triangle-cornercenter placement.

The authors speculate that for two cases, as the total gas flow rate increases, the value of $\mathrm{k}_{\mathrm{w}} \mathrm{A}$, the two phase interfacial area, the two phase transfer rate and the mixing degree will all increase. Therefore, regardless of the different placement of the bottom blowing tuyeres, the best mixing efficiency was found at total gas flow rate of $480 \mathrm{~L} / \mathrm{min}$. Moreover, in the case of $10.0 \mathrm{~mm}$ tuyeres in the squarecorner placement, the mixing degree of total gas flow rates ( 320 to $480 \mathrm{NL} / \mathrm{min}$ ) were approximate, then to consider the bottom blown operating efficiency, $480 \mathrm{NL} / \mathrm{min}$ was also an optimal selection.

\subsection{Actual operation in the ironmaking smelter}

The above discussions indicates that, the optimal blowing condition would be four tuyeres of $10.0 \mathrm{~mm}$ diameter in the square-corner placement under the total gas flow rate of $320 \mathrm{NL} / \mathrm{min}$ in the water model. As the air flow

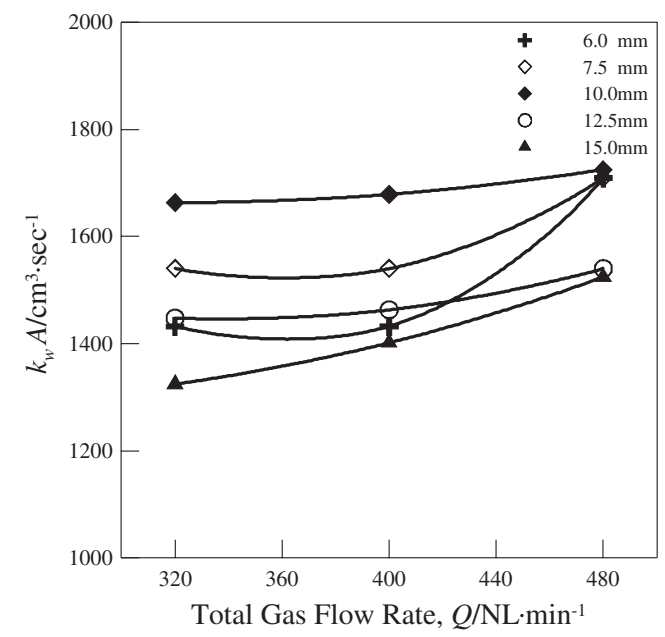

Fig. 12 Relationship between total gas flow rate and volumetric mass transfer coefficient in the case of four tuyeres with the square-corner placement.

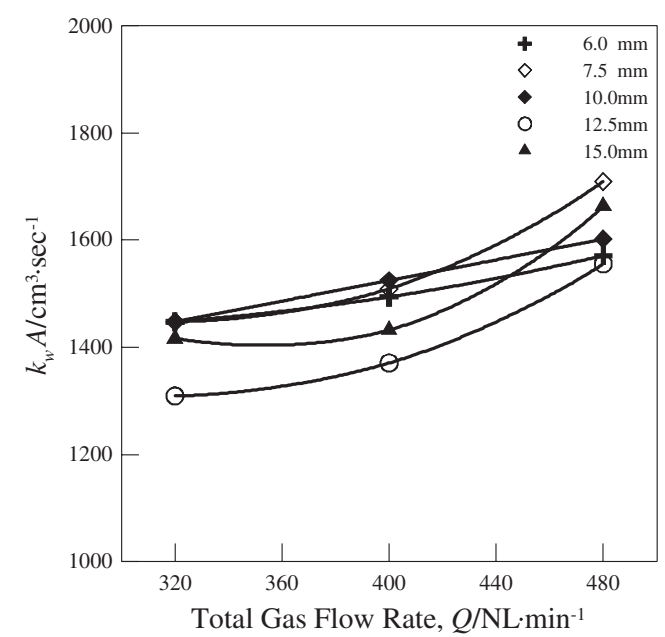

Fig. 13 Relationship between total gas flow rate and volumetric mass transfer in the case of four tuyeres with the triangle-corner-center placement.

rates of $320 \mathrm{NL} / \mathrm{min}$ via four tuyeres of $10.0 \mathrm{~mm}$ in the water model was further converted to the nitrogen gas flow rates via four tuyeres of $16.67 \mathrm{~mm}$ by eq. (11), a value of $1486 \mathrm{NL} / \mathrm{min}$ was then obtained and can be applied in the bottom blowing operation of the real ironmaking smelter.

\section{Conclusion}

(1) The volumetric mass transfer coefficient could be increased by increasing the total gas flow rate regardless of the tuyere size and the tuyere placement. The highest mixing degree was obtained at the total gas flow rate of $480 \mathrm{NL} / \mathrm{min}$.

(2) Under the total gas flow rate of $480 \mathrm{NL} / \mathrm{min}$, the highest mixing degree was obtained at the tuyere size of $7.5 \mathrm{~mm}$ diameter with 4 tuyeres in the triangle-corner-center placement and the tuyere size of $10.0 \mathrm{~mm}$ diameter with 4 tuyeres in the square-corner placement. While 
considering the both mixing efficiency and the energy consumption, the latter case would be the preferable choice.

(3) Considering both mixing efficiency and the gas consumption, the preferable choice of blowing condition would be four tuyeres of $10.0 \mathrm{~mm}$ diameter in the square-corner placement under the total gas flow rate of $320 \mathrm{NL} / \mathrm{min}$. Also, the actual operation in the real ironmaking smelter is four tuyeres of $16.67 \mathrm{~mm}$ diameter in the square-corner placement under the total gas flow rate of $1486 \mathrm{NL} / \mathrm{min}$.

\section{Acknowledgements}

The authors are grateful to the support from China Steel Corporation for this study.

\section{REFERENCES}

1) T. Sawada: Ironmaking Conference Proceedings (1995) pp. 499-506.

2) H. T. Tsai: Technol. Train, Taiwan (1997) pp. 54-73.

3) R. J. Matway, H. Henein and R. J. Fruehan: Trans. Iron Steel Soc. 13 (1992) 121-128.

4) D. Mazumdar and R. I. L. Guthrie: Metall. Trans. B 24 (1993) 649-655

5) T. W. Huang: Master degree thesis, I-Shou University, Taiwan, (2000).

6) S. H. Kim and R. J. Fruehan: Metall. Trans. B 18 (1987) 381-390.

7) Y. Kishimoto, Y. Sheng, G. A. Irons and J. S. Chang: ISIJ Int. 39 (1999) 113-122.

8) K. Krishnakumar and N. B. Ballal: ISIJ Int. 39 (1999) 1120-1124.

9) M. Y. Zhu, T. Inomoto, I. Sawada and T. C. Hsiao: ISIJ Int. 35 (1995) 472-479.

10) J. M. Chou, M. C. Chuang, M. H. Yeh, W. S. Hwang, S. H. Liu, S. T. Tsai and H. S. Wang: Ironmaking Steelmaking 30 (2003) 195-202.

11) S. Joo and R. I. L. Guthrie: Metall. Trans. B 23 (1992) 765-778.

12) S. I. Chung, J. H. Zon and J. K. Yoon: ISIJ Int. 31 (1991) 69-75.

13) H. Turkoglu and B. Farouk: ISIJ Int. 31 (1991) 1371-1380. 